\title{
Escultura ibérica de Espejo (Córdoba): Hipótesis sobre su funcionalidad
}

\author{
M. ${ }^{a}$ Rosario lucas \\ ENCARNACIÓN RUANO \\ JuAN SerRano
}

Por el Profesor Armin Stylow, conoció J. Serrano la existencia de esta nueva escultura ibérica. Su propietario es D. Antonio Romero Luque, al que agradecemos desde estas páginas las facilidades para realizar la descripción y fotografías.

Sobre las circunstancias del descubrimiento sólo cabe decir que se trata de un hallazgo fortuito, aparecido en las obras practicadas en una casa propiedad del señor Romero, situada junto a la muralla del castillo de Espejo, en la provincia de Córdoba (fig. 1).

Descripción (fig. 2 y 3): Se trata de un bloque prismático de piedra caliza, labrado regularmente por todas sus caras, aunque sólo una de ellas, la que consideramos el frente, ostenta decoración. La pieza está incompleta y, a juzgar por el remate superior, el bloque adoptaba forma antropomorfa. Actualmente ha perdido la parte correspondiente a la cabeza y está rota en el ángulo izquierdo (visión frontal) de la base, si bien esta rotura no afecta a la descripción general.

La altura media de lo conservado es de $43 \mathrm{~cm}$. La base rectangular mide $26 \times 24 \mathrm{~cm}$ y el ancho en la parte superior de los costados es de $11 \mathrm{~cm}$ (el perímetro de las caras laterales, formando trapecio, se ajusta a las medidas de 11 y $24 \mathrm{~cm}$ en lados menores y 45 y $43 \mathrm{~cm}$ en lados mayores). Es decir, el dorso es vertical, mientras el frente inclinado, alcanza $45 \mathrm{~cm}$ de longitud máxima. 


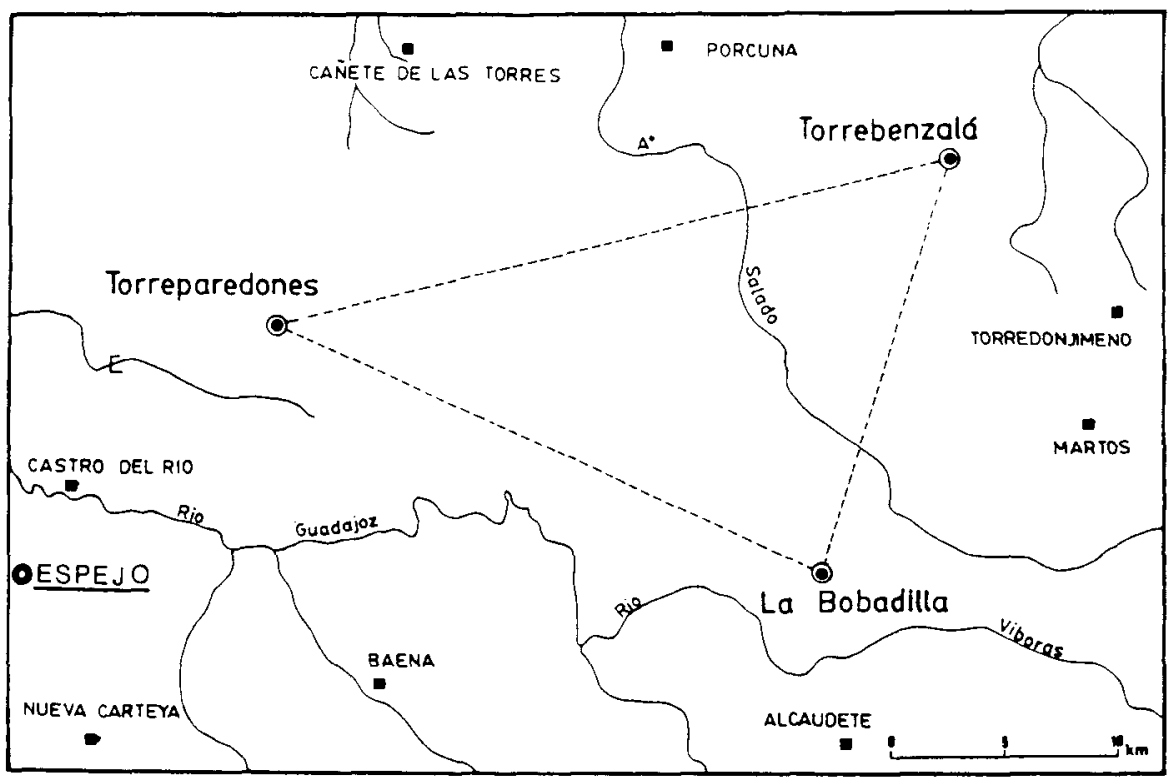

Fig. 1. Mapa de emplazamiento de Espejo y otros yacimientos próximos.

Aristas de base y cuerpo son rectilíneas, por la parte superior está ligeramente redondeada en los flancos y levemente inclinada en la cima, marcando de este modo los hombros del contorno antropomorfo cuya cabeza queda indicada por la rotura que afecta a la parte teórica del cuello (unos $8 \mathrm{~cm}$ de eje máximo).

El acabado de la pieza tiende a la regularidad pero es más tosco en la espalda y en la base, con el perímetro interno ligeramente realzado. Los flancos, aunque sin decoración, fueron cuidadosamente alisados, al igual que los hombros y el anverso, la única parte decorada. Estos detalles hacen pensar que importaba fundamentalmente la visión frontal.

Técnicamente la decoración puede calificarse de suave relieve (apenas unos $3 \mathrm{~mm}$ ) si bien esta técnica solamente se ha empleado para destacar el dibujo de los miembros superiores, doblados en ángulo (fig. 2.3). Los brazos, desproporcionadamente largos y en plano más alto que el resto de la figura, coinciden con los límites del contorno, y los antebrazos, apoyados en el torso, muestran una posición asimétrica: más alto el derecho que el izquierdo. De las manos queda una huella rectangular y el testimonio de los dedos de la mano derecha, así como la evidencia de que no estaban unidas. La fuerte incisión que delimita el relieve, así 


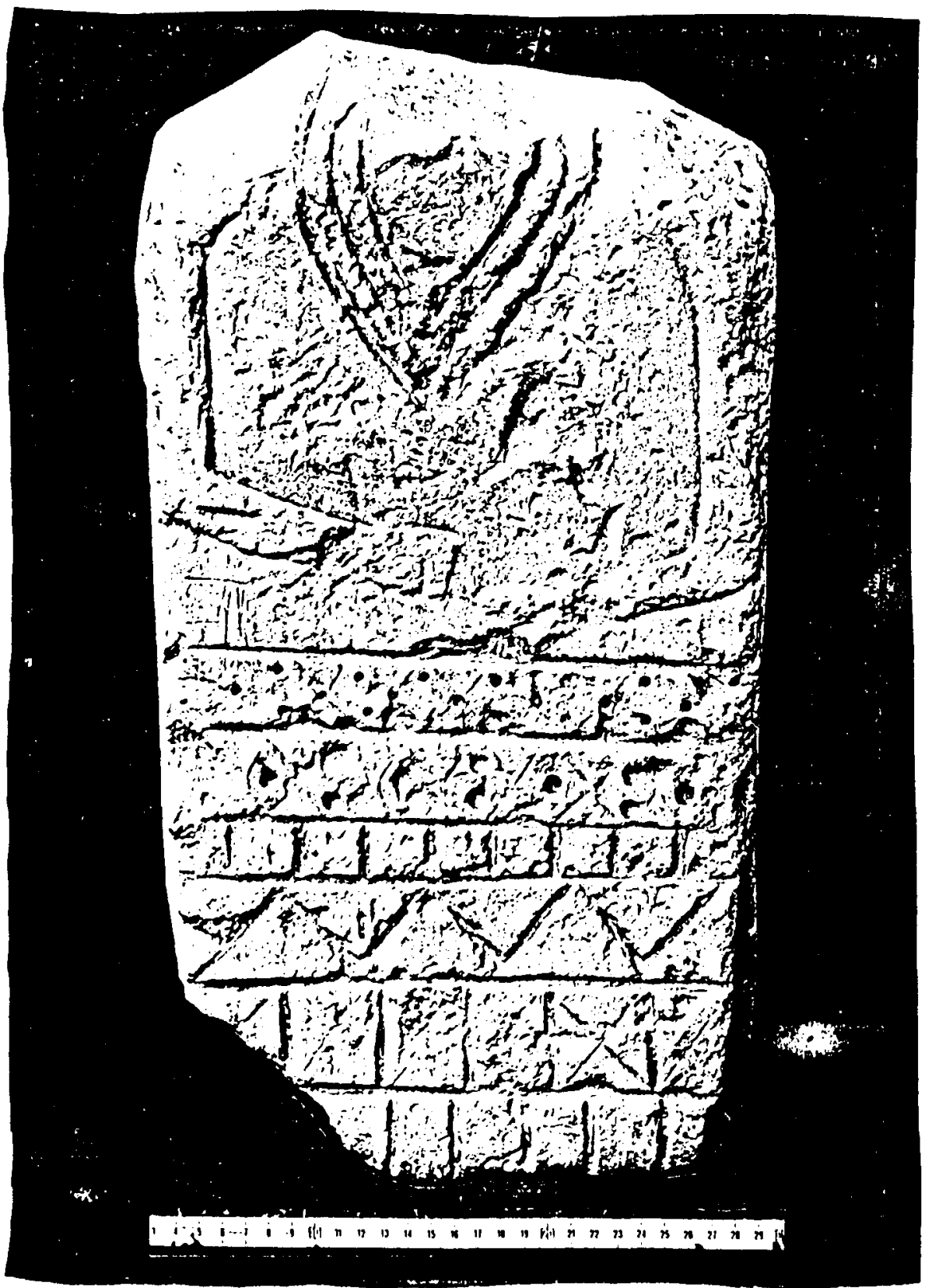

Fig. 2. "Dama" de Espejo (Cordoba). 
$M{ }^{a}$ ROSARIO LUCAS, ENCARNACION RUANO Y JUAN SERRANO

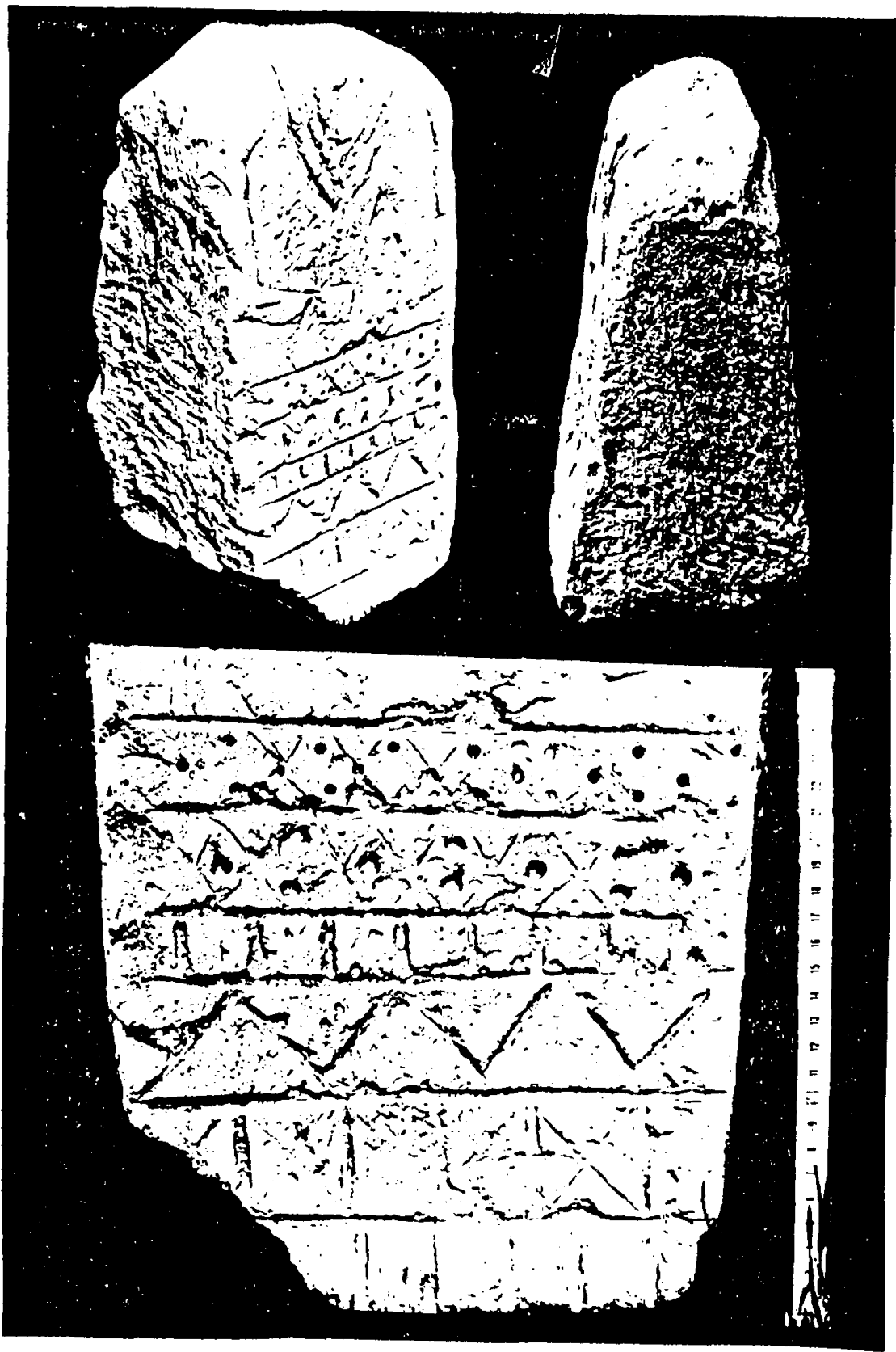

Fig. 3. Dama de Espejo. Vista lateral y detalle del atuendo. 
como unas suaves lineas apreciables bajo el brazo derecho, como si se tratara de un tanteo desechado, permiten asegurar el ductus previo del dibujo, antes de rebajar el volumen deseado para destacar los brazos, salvando, mediante pulimento final, la homogeneidad de la superficie.

El resto de la decoración está lograda mediante incisión profunda y conformada por los siguientes elementos:

a) Tres fuertes líneas, a modo de surcos trazados a bisel, ascienden hasta rodear el cuello y representan lo que puede ser un collar de dos vueltas acoplado al escote en pico de la posible túnica.

Toda esta zona - de los brazos al escote - muestra superficialmente alteraciones y raspaduras, especialmente a la altura hipotética de los pechos, vicisitudes que dan la sensación de confusos dibujos, con seguridad ajenos al trabajo primitivo.

b) Aproximadamente hacia la mitad de la pieza un surco perfectamente horizontal (anchura media $5 \mathrm{~mm}$ ) dá paso al cuerpo inferior ricamente ornamentado con seis franjas paralelas, separadas entre sí por los respectivos filetes muy similares entre sí. La descripción, de arriba a abajo, es la siguiente (fig. 3.3):

1. Cadena de losanges marcados por una fina incisión. Interiormente, y tendiendo a coincidir con los vértices, aparecen profundas puntuaciones $(7 \mathrm{~mm})$ de diámetro muy regular $(5 \mathrm{~mm})$. Anchura media del interior de la cenefa: $21 \mathrm{~mm}$.

2. Cadena de idéntico diseño geométrico complementado con puntuaciones, en este caso de mayor diámetro $(7,5 \mathrm{~mm})$ y distinta cadencia (al tresbolillo): alternancia de uno y dos puntos cada dos rumbos. Anchura media: $33 \mathrm{~mm}$.

3. Líneas verticales paralelas y profundas trazando rectángulos. Se aprecia sendas puntuaciones, menos profundas que las anteriores dispuestas desmañadamente. Anchura media $20 \mathrm{~mm}$.

4. Línea profunda en zig-zags (crea tres triángulos y medio). Anchura: $40 \mathrm{~mm}$.

5. Repite el modelo de la cenefa 3 , pero cada cuartel rectangular se adorna con un aspa finamente incisa. El desgaste superficial de esta banda no clarifica regularidad de puntuaciones. Anchura media: $40 \mathrm{~mm}$.

6. La última cenefa muestra únicamente líneas verticales profundas, creando cuadros, a manera de la anterior y libre de cualquier relleno. Anchura media: $26 \mathrm{~mm}$. 
Técnicamente, como se aprecia en las fotografías, además de lijas y otro instrumental propio y lógico en los trabajos de canteria, se discierne el uso de cincel en rebajes y surcos, buril o similar para incisiones menos profundas y, lo que es más importante, la posibilidad de utilizar el trépano en el perfecto trazado de los agujeros o puntuaciones más profundas.

Por otra parte, hay que remarcar que los dibujos debieron complementarse con incrustaciones de otra materia, resaltando diferencias cromáticas. Al menos en el interior de las lineas más profundas se nota la existencia de una especie de pasta o estuco. Además la tonalidad rojiza de los gruesos puntos de la cenefa 2 hacen pensar en diferente cromatismo e incluso es posible que los puntos de la cenefa 1 se relienaran con alguna materia más especial.

\section{ESTUDIO ANALÓGICO}

La ausencia de contexto y las circunstancias fortuitas del hallazgo fuerzan a estudiar la pieza por el único método posible, la analogía morfológica y decorativa.

Adelantamos que la clasificación de ibérica viene corroborada por cuanto hoy conocemos sobre este tipo de plástica, localizada en diferentes puntos del área ibérica.

En un amplio trabajo sobre escultura ibérica (RUANO, E., 1987) quedó demostrada la existencia de dos tendencias en las representaciones humanas; a la serie que denomina esquemática se adscribe este ejemplar caracterizado por la simplificación de la anatomía corporal, pese a resaltar las partes que interesan al artista y a los objetivos de la figuración: cabeza, brazos y riqueza de adorno personal.

La serie, en general, (IV de la mencionada referencia) ${ }^{1}$ no muestra uniformidad en la silueta puesto que el bloque antropomorfo adopta forma cilíndrica, prismática o piramidal. Los brazos, tendentes a un mayor vo-

1 Al inventario y blibliografía recogida por $E$. Ruano debe añadirse el artículo de esta autora y SAN NiCOLAS, M., (Exvotos ibéricos procedentes de La Encarnacion (Murcia)), que será publicado en el Homenaje a E. Cuadrado, editado por el Museo de Murcia y la publicación de Morena, J. A., (Santuario ibérico de Torreparedones, Castro del Río-Baena (Córdoba)) publicado por la Diputación de Córdoba en 1989. 
lumen, en posición flexionada, pegados a los contornos o sobre el pecho, son atributos preferentes, y entre otros rasgos hay que destacar su pequeño tamaño, la individualización de manos y dedos y muy especialmente la tosquedad del rostro.

Atendiendo a la diferenciación de los hombros y a su trazado en diagonal, así como al contorno general del bloque, apuntamos como paralelos morfológicos más próximos, los siguientes ejemplares:

- Entre las piezas del conjunto votivo procedente de Torreparedones (Córdoba) y publicadas por J. A. Morena (1989) son de notar las esculturas representadas en las láminas XVII (alt. $26 \mathrm{~cm}$ ), XVIII (alt. 22 $\mathrm{cm}$ ), XXXII (alt. $11 \mathrm{~mm}$ ), etc. (Vide reverso en lám. LVI). De este yacimiento proceden las ilustraciones núm. 3 a 5 de la figura 4 .

- Esculturas J-10 (13 cm de altura) y J-B $(25 \mathrm{~cm})$ del conjunto votivo de la Torre de Benzalá (Torredonjimeno, Jaén) (fig. 4.1).

- Esculturas AB-81 (32 cm de altura), AB-263 y AB-335 (13 cm de tamaño) procedentes del santuario del Cerro de los Santos, Montealegre del Castillo (Albacete) (RuAno 1987).

Aparte de estos paralelos, con ciertas semejanzas, pero no similitud, debe recordarse el ejemplar acéfalo, localizado en 1935 por Chocomeli en la cima del Tossal de la Serrá, término de Ares del Maestre (Castellón). Teniendo en cuenta que esta pieza (fig. 5.3) apenas es citada en la bibliografía trascribimos la descripción que sobre la misma realizó en su día I. Ballester Tormo (1942, pág. 129-132, lám. Xll):

Estela ibérica labrada. Fórmala una piedra troncopiramidal, muy alargada y estrecha $(840 \mathrm{~mm}$ de alto por 185 de ancho medio, y 100 de grueso), con basto raigón en la base para sujetarle al suelo, y rota por la parte superior, que lleva esculpida en una de las caras mayores una incompleta figura de dama ibérica. Los bordes resaltados de la cara labrada fueron ornados con un grupo de líneas en zig-zag continuado que parecen indicar los bordes del manto. Desaparecido de antiguo el extremo donde debió labrarse la cabeza, muéstranse en lo que queda de parte alta, correspondiente al pecho, dos gruesos collares con tres colgantes discoidales de tamaños graduales. A como dos tercios del extremo superior, una amplia zona transversal, delimitada por bordones resaltados, y rellena de reticulado inciso, da la impresión de faja o cinturón de la figura, del que pende una fila de colgantes circulares; y la larga túnica remata, por bajo, en una resaltada franja ornada de serie de cuadradillos con circulitos en el centro. No hay la menor indicación de pies y de brazos, como dando aquéllos por cubiertos por el borde de la túnica y 

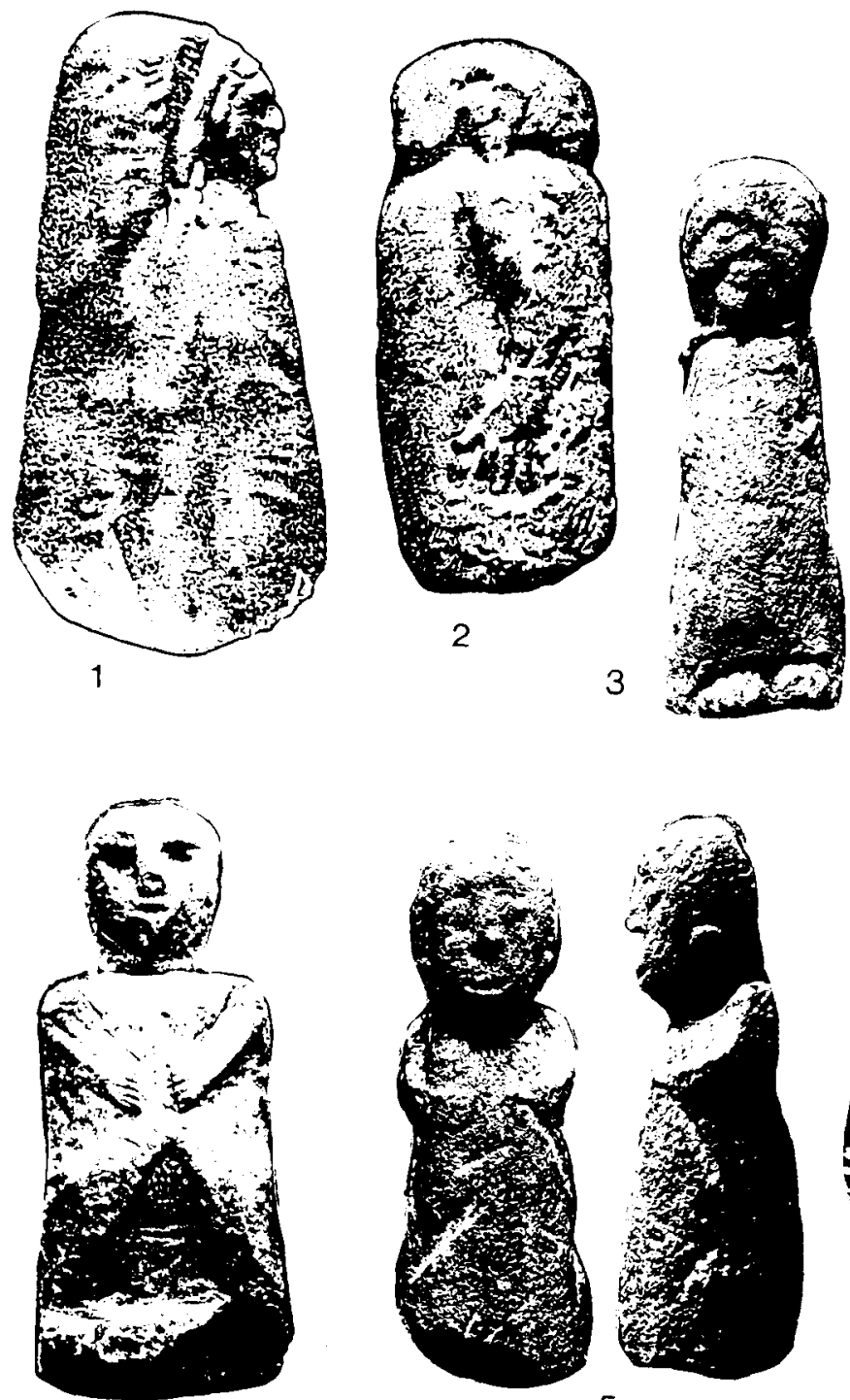

4
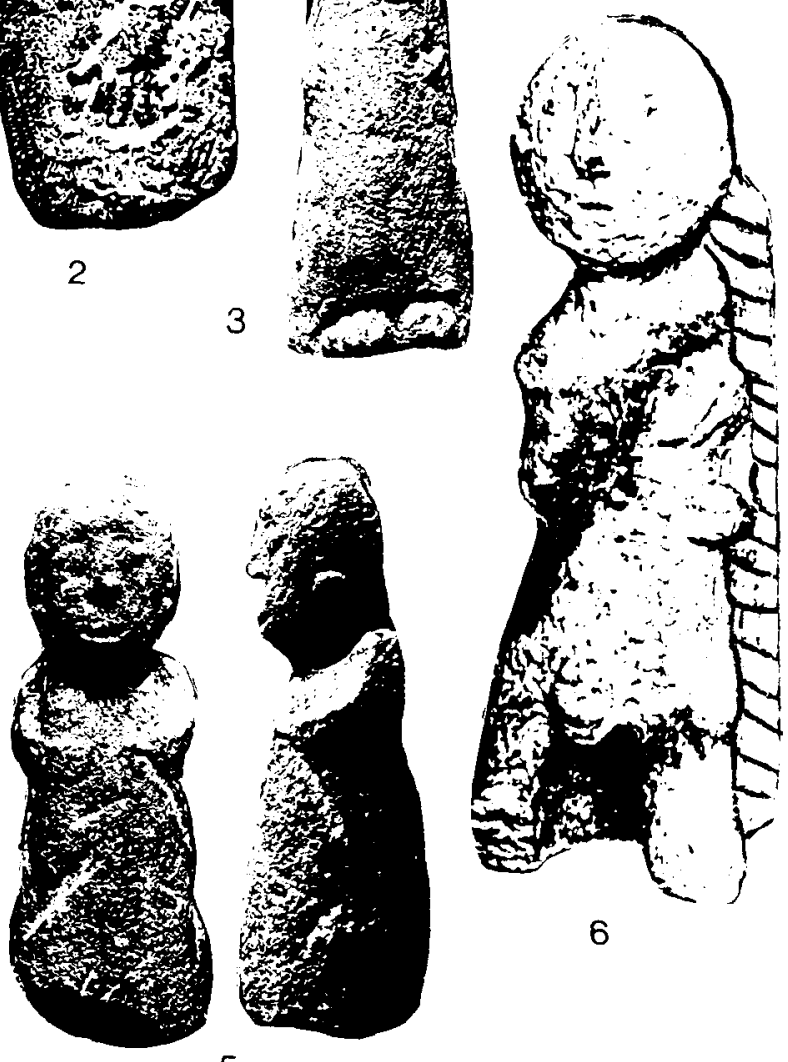

6

Fig. 4. Esculturas ibéricas esquemáticas:

1. Torre de Benzalá (Jaén).

2. Caravaca (Murcia).

3. a 5. Torreparedones (Córdoba).

6. Cerro de los Molinillos (Córdoba). 

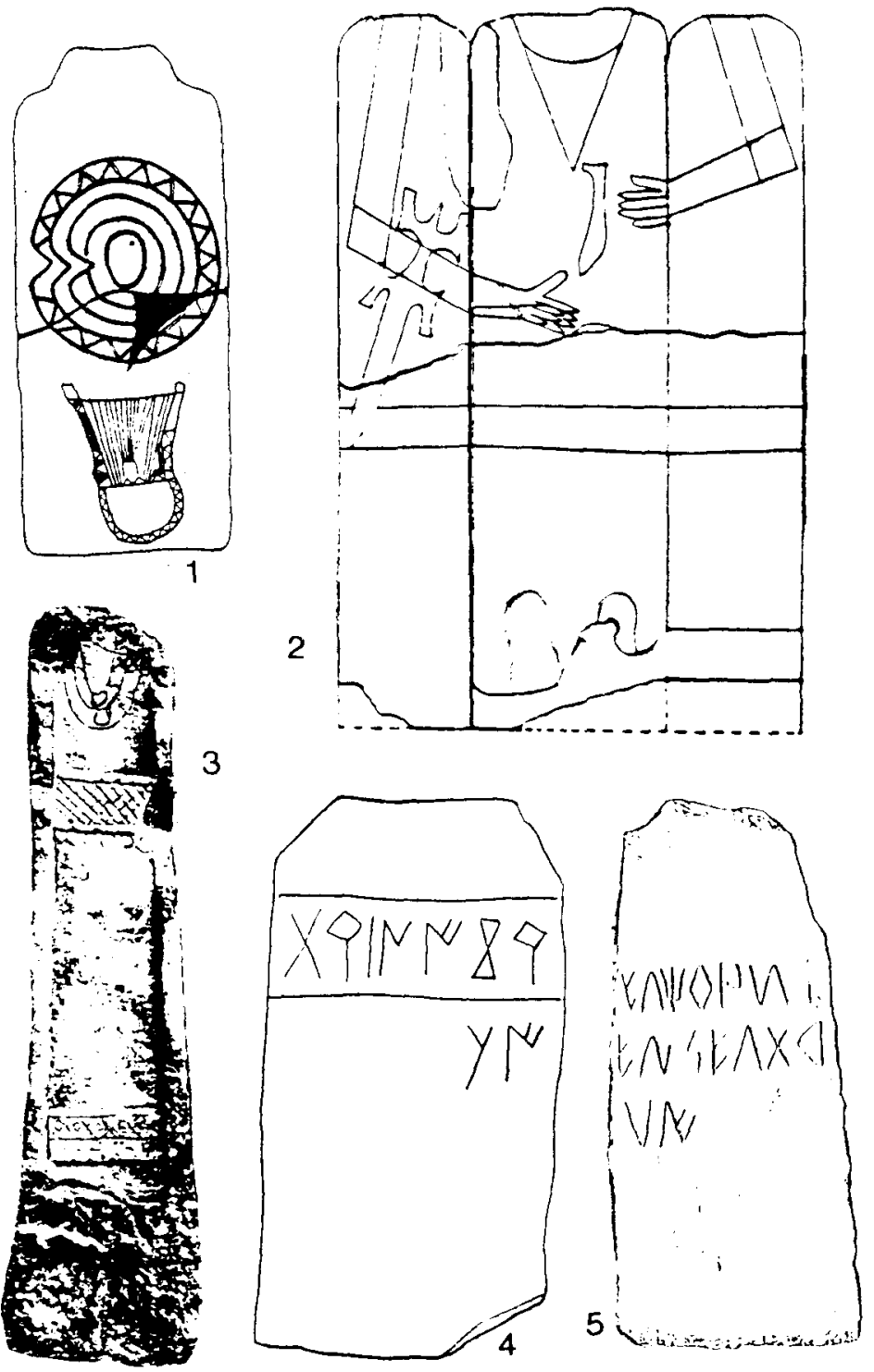

Fig. 5. Estelas de contorno antropomorfo:

1. Luna (Zaragoza).

2. Altea la Vella (Alicante).

3. Ares del Maestre (Castellón).

4. Canet lo Roig (Castellón).

5. Cabanes (Castellón). 
éstos por el manto. Es bien de lamentar que la rotura, de antiguo, del extremo en que iba la cabeza, nos impida conocer detalles de la misma; habiendo sido inútil su búsqueda en el terreno inmediato al sitio de hallazgo.

Sobre las circunstancias del hallazgo se indica que fue encontrada rota en dos pedazos, en los campos aledaños del Tossal, colindantes con el monte. En el lugar aparecieron "unos pocos huesos que se creen humanos" y dos "piedras circulares de molino ibérico".

La comparación con la pieza de Espejo muestra diferencias respecto al tamaño (más alta y excesivamente delgada la de Castellón) y modo de rematar los bordes (sobreelevados y decorados en la valenciana, seguramente para indicar el manto). La calificación de estela por parte de Ballester Tormo se fundamenta en el "basto raigón", que, a juzgar por la ilustración, se trata de un cuerpo inferior más ancho (unos $20 / 25 \mathrm{~cm}$ ) delimitado por debajo del supuesto borde de la túnica. La erosión de la superficie, coincidiendo con esta zona basal, sirve de argumento para explicar que la escultura estuvo hincada en la tierra.

Si la hipótesis es correcta la escultura de Ares proporcionaría el testimonio de la utilización de estatuas/estelas en el mundo ibérico. En este caso la altura externa de la figura humana equivaldria a la cordobesa de Espejo, con la que coincide también en los siguientes aspectos:

- Morfologia del bloque monolítico.

- Silueta de contorno antropomorfo (cabeza destacada del cuerpo y ausencia de extremidades inferiores).

- Ornato del atuendo: collares y bordado geométrico de la túnica.

No obstante, también existen diferencias:

- El bloque de la pieza de Ares es mucho más estrecho $(18,5 \mathrm{~cm})$ que el utilizado en Espejo $(26 \mathrm{~cm})$.

- La "estela" de Castellón carece de la representación de brazos ${ }^{2}$, particularidad que si se aprecia en las citadas esculturillas de Torreparedones, Torre de Benzalá y Cerro de los Santos, que, sin embargo, carecen de collares y difieren en tamaño.

- Los collares adoptan forma elipsoidal en la escultura de Ares mientras los correspondientes a la de Espejo caen formando pico.

2 La falta de claridad en la fotografia nos hace dudar de si la representación de los brazos se ha reducido a unos muñones coincidentes con los bordes resaltados de los laterales. Si así fuera, la pieza aumentaria su interés por el paralelismo que podría existir con algunas esculturas femeninas de El Cigarralejo (Mula, Murcia). 
- Organización diferente del vestido y su adorno. La "dama" de Espejo no lleva franja en el pecho y la decoración, muy profusa, abarca casi la totalidad de la falda; en cambio la de Ares lleva sólo dos franjas yuxtapuestas al borde de la túnica y el realzado de los bordes indica el complemento de un manto, ausente en la pieza cordobesa y muy raro en la serie de las esculturas "esquemáticas".

Al comprobar las afinidades en una pieza geográficamente tan alejada y valorando también las diferencias (especialmente el tamaño) respecto a las esculturas esquemáticas de los yacimientos más próximos (fig. 1) como son Torreparedones y Torre de Benzalá, nos planteamos la hipótesis de hasta qué punto la escultura de Espejo, de mayor tamaño, pudo tener la funcionalidad de una estela.

A dar respuesta a esta hipótesis se dedican las próximas líneas, partiendo de una valoración global de las estelas de soporte antropomorfo en la Península, con especial dedicación a las exclusivamente ibéricas.

\section{APROXIMACIÓN A LAS ESTELAS}

En la larga tradición de las estelas hispanas, los tipos de silueta antropomorfa pueden ser muy antiguos. Su distribución afecta prioritariamente al occidente de la península (BARCELO, J. A. 1988), pero piezas como la de Asquerosa o Lantejuela se sitúan en Andalucía e inclusive la dispersión rebasa el valle del Ebro, como desmuestran los ejemplos de Logroño y Cataluña mencionados más adelante, además de existir otros modelos de soportes como documenta la excepcional estela de Preixana (Lérida) (MAYA 1977, pág. 95). No obstante, interesa aproximarnos a las estelas de fecha más reciente y en este sentido la primera pieza que reclama nuestra atención es la llamada estela de Luna o Valpalmas en Zaragoza (FATAS, G. 1975) relacionada, por la representación del escudo, (fig. 5.1) con las llamadas "Estelas de Suroeste» adscritas al Bronce Final. En cualquier caso la estela aragonesa se aparta de esta serie, no sólo por su posición geográfica, aspecto hoy irrelevante dada la amplia dispersión en la Peninsula, incluida la provincia de Córdoba, y la reciente localización de dos nuevos ejemplares en el Sur de Francia, sino porque el contorno, perfectamente trabajado y regularizado en esbelto bloque prismático de proporcionadas medidas, es antropomorfo y diferencia per- 
fectamente los hombros inclinados y el cuello, aunque desgraciadamente se haya perdido la cabeza.

Ignoramos si existe en el sector Noreste una tradición continuada de estelas que sirva de antecedente a este tipo de representaciones, independientemente de su iconografía, pues los ejemplos de estelas antropomorfas especialmente más próximas son, por una parte, las tres localizadas en Alberite (Logroño), sin duda mucho más antiguas, pero caracterizadas por la representación de ambos sexos, gran tamaño (faltan las cabezas), delgadez del cuerpo prismático (media de $1,50 \mathrm{~m}$ por 40 de anchura y 20 de espesor) y hombros rectilíneos bien marcados, (TARACENA, B. 1940/41 y CASTiELLA, A. 1977, pág. 118-119). Por otra, aunque los datos sean confusos, en la región catalana no se deben olvidar las llamadas piedras decoradas de Passanant y otros testimonios recogidos en la mencionada publicación de Maya. A ello hay que añadir, siempre en relación con las necrópolis atribuidas a los Campos de Urnas, citas aisladas sobre la presencia de toscas estelas anicónicas ${ }^{3}$, remedando el contorno antromorfo, a las que se ha dado poca importancia en la investigación (en el campo G de la necrópolis de Roques de Sant Formatges en Pedrós, Lérida, una de estas toscas losas se halló hincada en la tumba 290 según Pita Mercé y Díaz Coronel, 1968). Un raro ejemplar de tendencia antropomorfa muy esquemática es, precisamente, otra estela localizada en la necrópolis de La Pedrera, en Valfogona de Balaguer (Lérida), sin asociación precisa de materiales, pero evidentemente dentro de la etapa del Hierro. Se trata de un bloque monolítico en el que destaca la base ensanchada, reforzando su función de pedestal, prolongada en un cuerpo, pudieramos decir betílico, coronado por la representación resaltada del rostro en el que destaca la nariz (MAYA 1977, pág. 95, fig. 90).

Más cercanos en el tiempo, avanzando la cultura ibérica, contamos ya con un buen repertorio de estelas localizadas en territorio aragonés, documentando con ello, si realmente se acepta la función de hitos funerarios, la costumbre de señalar las tumbas con este tipo de monumentos, temporalmente próximos a las estelas con epigrafía ibérica procedentes de Castellón (OLIVER, A. 1978). Ciertamente las estelas decoradas del Bajo Aragón (Marco, F. 1978; Martín Bueno y Pellicer, M. 1979/80; RUANO, E. 1990) no ostentan contorno antropomorfo, por ello llama más

${ }^{3}$ En el Coloquio Internacional sobre Religiones Prehistóricas celebrado en Salamanca Nuria Rafel y otros dieron a conocer un túmulo de la necrópolis de Coll del Moro de Gandesa (Tarragona) en el que estaba hincada una de estas estelas anicónicas. No se puede descartar una decoración mediante pintura. 
la atención que sea el territorio valenciano del Maestrazgo, donde la escultura ibérica tiene tan escasa representación, el que haya proporcionado la mencionada estala de la "dama del Tossal de la Serrá".

Centrados en Castellón, un argumento en favor de la relación entre estelas funerarias anepigráficas y epigráficas, lo proporciona la pieza de Bell-Lloc en la Plana Alta de Castellón, fechada por F. Arasa (1989) hacia los siglos $\|-1$ a.C. En el frente aparece la inscripción y una cartela doble, pero el soporte, conservado en la parte superior (unos $30 \mathrm{~cm}$ ) no deja lugar a dudas sobre el contorno antropomorfo de la silueta, apuntado ya en otras estelas con escritura ibérica localizadas en las proximidades, siempre en la zona Norte del territorio valenciano. Estelas como las de Canet lo Roig (fig. 5.4), Benasal y Cabanes (fig. 5.5), aunque mutiladas y acéfalas, conservan la forma oblicua de los hombros (FLETCHER, D. 1985 y ESTÉVEZ, F. 1989) reforzando con ello la perduración de posibles antecedentes dentro del sustrato.

En favor de esta tradición, y como hipotético enlace entre las estelas más recientes y las de tipo antropomorfo con representación de armas (caso del ejemplar de Valpalmas) no se puede olvidar el hallazgo en la necrópolis ibérica de Altea la Vella (Alicante) de una estela (MOROTE, G. 1981) conservada en el Ayuntamiento del municipio (fig. 5.2). Se trata de una rara pieza cuyo contexto arqueológico se conoce con cierta precisión. El ajuar, atribuido a una incineración, están formados por «urnas de orejetas", dos broches de cinturón de tres garfios y un fragmento de cerámica clasificada como ática (?). La pieza, una vez más está acéfala y algo incompleta en la parte inferior. Mide $108 \mathrm{~cm}$ de long., $29 \mathrm{~cm}$ de ancho y $20 \mathrm{~cm}$ de grosor; es decir, priva la tendencia longitudinal del bloque prismático. Los hombros, suavemente redondeados, también son inclinados. Está trabajada en todos sus frentes indicando mediante incisión los rasgos que interesó destacar. El cinturón, una banda simple, es elemento común a todas las superifices, asímismo el escote en pico y la marca de una camisa o prenda interior aparecen en anverso y reverso. Los brazos acodados se marcan ya en los laterales, prolongándose hasta la cara frontal en donde se dibujaron el extremo de los antebrazos y las manos, apoyados sobre el pecho a distinta altura, en posición semejante a los de la escultura de Espejo.

La estela de Altea la Vella se individualiza además por tener representada en la parte inferior del anverso la silueta de los pies, hoy incompletos, en rara perspectiva frontal, como queriendo acercarse a las esculturas de bulto redondo. La atribución masculina se infiere por la presencia de armas: en el lado izquierdo del pecho un cuchillo afalcatado y colgado del antebrazo derecho, con la punta sobre el cinturón, un puñal 
cuya representación se sitúa en el lateral correspondiente (el tamaño de la hoja en relación con la empuñadura impide catalogarlo como espada). Este arma, sin lugar a dudas, es la pieza más interesante. No pretendemos hacer un estudio exhaustivo de esta estela alicantina, sino llamar la atención sobre las razones de su cronología. El tipo de puñal es ciertamente extraño. La hoja, con el arranque despegado de la embocadura, es de filos paralelos y punta aguzada y la empuñadura tiene un aspecto antropomorfo, propiciado por la simetría de pomo y guardas en $U$ de ramas cóncavas y agudas esquinas, asi como por la prolongación o sujección del huso rematando en exagerado pico ${ }^{4}$.

No se ha documentado en la Península Ibérica ningún puñal que responda estrictamente a esta morfologia, si bien es posible citar algunas referencias de valor cronológico puesto que la forma de la guarnición enlaza con los modelos europeos de «tipo Hallstat» en pleno desarrollo durante la etapa D1 (WERNER, T. 1984, lám. 2, fig. 3). Se caracteriza por las antenas en media luna rematadas en disco y guardas en $\mathrm{U}$ con ramas despegadas de los filos, así como espiga traspasando la cruz y acabada en una bola. En España las armas que siguen esta tipología, independiente de los prototipos del modelo gallego representado por el puñal de tipo Couboueria, se localizan en el NE y los paralelos más próximos aparecen en la vecina Francia asociados a las incineraciones de la primera Edad del Hierro. En cualquier caso, los ejemplos más afines, pese a diferencias en la guarda, se hallan, por una parte en la espada de antenas de Fila de la Muela (Alcorisa, Teruel), con crucero formalmente similar al dibujado en la estela (ALVAREZ, A. y otros 1980); por otra, tanto en espadas como en puñales localizados en necrópolis del Sur de Francia como Les Peyros en Couffoulens (SOLIER, J. y otros 1976). Cuchillos afalcatados y broches de cinturón de uno o más garfios son frecuentes en estos conjuntos, tan afines a los del Noreste hispano que incluyen a la vez urnas de orejetas, con la ventaja de que los materiales importados permiten fechas bastante aquilatadas, caso del célebre ajuar del guerrero de Corno Lauzo en Mailhac (TAFFANEL, O. y J. 1960) que contiene una espada con este modelo de empuñadura, acompañado de un ánfora etrusca, una copa de los pequeños maestros y otra jónica de tipo B2, testimonios del servicio para la bebida depositado en la tumba hacia el último tercio del siglo vi. Asi pues, los paralelos del puñal llevan, sin contradicción con el ajuar, a atribuir a la estela de Altea la Vella una

4 Las empuñaduras auténticamente antropomortas con los rasgos humanos individualizados y reducidos brazos y piernas y apéndices arqueados se fechan en el siglo $\|$ a. de $C$. 
fecha de hacia fines del siglo vı a.C., en un momento antiguo de la cultura ibérica.

Si se tiene en cuenta los hallazgos citados, su distribución espacial $y$, sobre todo la sucesión cronológica, es lícito aceptar, entre los monumentos ibéricos indicadores de tumbas la existencia de estelas. En tal sentido ya se pronunció Santos Gener en 1950, al dar la calificación de estela, basándose precisamente en el hallazgo castellonense de Benasall, a la pieza del Museo de Córdoba inventariada con el número 4.348, recogida en terrenos industriales de la ciudad. La describe en los siguientes términos: "Representa una cara femenina adosada a una estela prismática rectangular, la cara, en alto relieve y oval esta tocada con una tiara de dibujo ajedrezado y adornan su cuello varios collares de cuentas cónicas, como los de las estatuas del Cerro de los Santos. El aspecto del rostro es torvo, por tener las cejas unidas en linea recta y ojos tangentes a ellas, nariz en forma de prisma rectangular y la boca es una fisura sin labios".

En verdad, muchas de estas citas son confusas, falta el contexto y las piezas están muy fragmentadas. Pese a ello, recordamos otra escultura (Ruano, E. 1981, pág. 45) del Museo de Córdoba, procedente del Cerro de los Molinillos en Albendín (Baena). Representa (fig. 4.6) en altorrelieve un varón desnudo de enorme cabeza en la que se aprecia el pelo en zig-zags, frente despejada, ojos redondos y expresivos y larga nariz. La boca se reduce a una ranura y es posible que se adornara con un collar. La posición estante muestra bien diferenciados los hombros oblicuos, el sexo y las piernas abiertas (rotas a la altura de la rodilla). La posición de los brazos es flexionada hacia arriba y se apoyan sobre el pecho. La particularidad más importante de la figura es su labrado sobresaliendo del un bloque monolítico y prismático $(44 \mathrm{~cm}$ de altura conservada por $17 \mathrm{~cm}$ de ancho y $15 \mathrm{~cm}$ de espesor) cuyos bordes rematan en una especie de sogueados.

Es obvio que no debemos desdeñar la función de estela funeraria para algunas esculturas ibéricas, sobre todo teniendo en cuenta la larga tradición de estos monumentos con anterioridad a esta época y la amplitud geográfica. Por otra parte, también deben valorarse las costumbres que han podido influir a no olvidar este tipo de señalización. En tal sentido, hemos de recordar, se llamen cipos o estelas, los documentos de las necrópolis púnicas, caracterizadas, en términos generales por un cuerpo prismático de coronamiento variable. Entre los nuevos hallazgos están los relacionados con algunas de las tumbas más antiguas de lbiza (Puig de Molins, Sector de Can Partit), fechables por los materiales en el siglo vi a. C. (Gomez Bellard, 1990, passim, lám. LXX) y tienen la 
particularidad de estar formados por un bloque tronco piramidal de unos $40 \mathrm{~cm}$ de altura en cuyo frente destaca, mediante entalles, una especie de disco (equivalente por tanto a la cabeza de las estelas que nos ocupan). Los restos de pintura indican la pérdida de la decoración o el texto de un epitafio.

P. Cintas (1976, T. II, 359-360) diferencia claramente la función funeraria de la votiva de las estelas púnicas. En la variedad de modelos recogidos en su lámina LXXII, destacan dos ejemplos, masculino y femenino caracterizados por el contorno antropomofo, rastos corporales muy sumarios (centrados en los brazos) y detallada cabeza. El bloque incluye y diferencia en la morfología un «raigón» para hincar en el suelo, parangonable, salvando las distancias de los detalles artísticos y de la existencia de cabeza, con la estela de Ares.

No queremos abundar en la larga tradición de estelas funerarias en todas las culturas del Mediterráneo, pero hemos de recordar el auge que, a partir de lo villanoviano, adquieren estos monumentos en Italia prerromana. Dentro de la variedad es común el remate discoidal, remedando la silueta antropomorfa y con alusiones en el frente a la condición de guerrero, como en el caso de las estelas de Etruria, Daunia o del Piceno (siglos VII y vi a. C.), diferentes respecto al tratamiento frontal, pero coincidentes en utilizar un bloque muy alargado e indicar claramente los hombros. La estela de Valpalmas y de Altea podría encerrar conceptualizaciones comparables, reflejadas más sumariamente y con representación de ambos sexos en las estelas atestinas y ligures, reducidas a un tosco bloque monolítico, destacando mediante suaves relieves la anatomía corporal o las armas. Las estelas menhires-antropomorfas de la isla de Córcega también persisten hasta bien entrado el primer milenio, como demuestran los cuerpos reducidos a un herma.

En el estado de la cuestión, la distribución geográfica de las estelas de contorno antropomorfo (fig. 6) y destino funerario dentro del área ibérica, conjuga claramente la hipótesis de que los antecedentes del sustrato se hayan reforzado con modelos foráneos. En este sentido, la estela de Ares del Maestre se aproxima a la rareza de las estatuas/estelas del Museo del Bardo, ciertamente tardías (la masculina de Gammart se fecha en el siglo III a. C.) e influidas por lo griego, pero mantiene el gesto indigena de la estela de Altea en la que se representó escote y cinturón, elementos sustituidos en las piezas femeninas de Ares del Maestre y en la de Espejo por los collares y el detalle de la vestimenta, atributos normales en las esculturas propiamente ibéricas. 


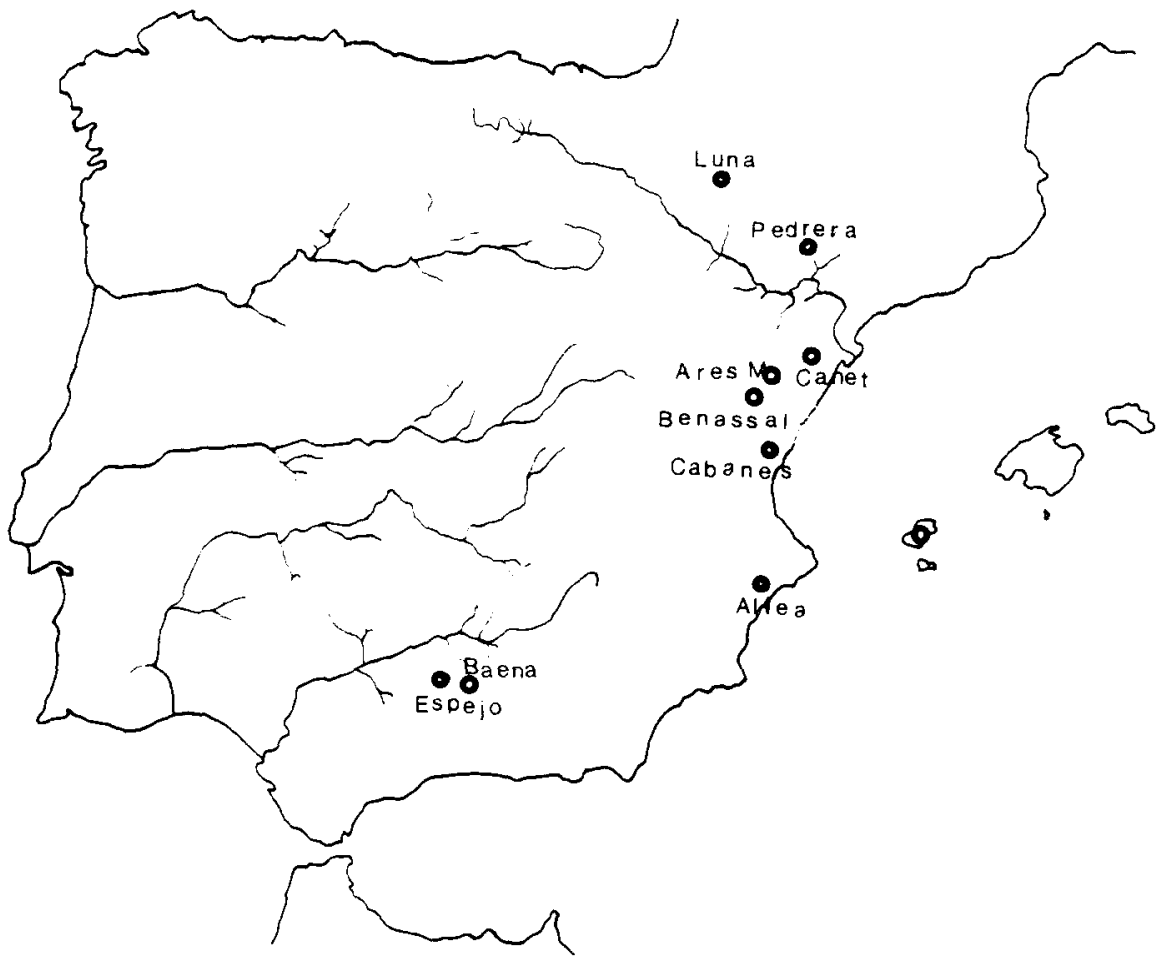

Fig. 6. Mapa de dispersión de las estelas de contorno antropomorfo atribuibles al Hierro I y 1 .

\section{CONCLUSIONES}

No podemos demostrar, por carecer de contexto, que "la dama" de Espejo haya tenido función funeraria, pero ante las diferencias de tamaño (Vide cuadro adjunto) respecto a las esculturas ibéricas de carácter votivo, mencionadas al principio, y teniendo en cuenta la similitud morfológica y ornamental con la escultura femenina de Ares del Maestre, tan singular por su localización geográfica y cuyo destino como hito funerario es razonable, dadas sus circunstancias, altura y remate basal, nos inclinamos a atribuir la función de estela funeraria a la pieza procedente de Espejo, dejando abierta la hipótesis de que también lo fuera la figura varonil localizada en el Cerro de los Molinillos.

Es lógico pensar que entre los monumentos funerarios indicadores de tumbas ibéricas existieran auténticas estelas, en línea con la tradición 


\begin{tabular}{|c|c|c|c|}
\hline Torreparedones & 11 a 26 & Altea & $108 \times 29 \times 20$ \\
\hline Torre de Benzalá & 13 & Cabanes & $105 \times 45 \times 26$ \\
\hline Caravaca .. & 25 & Bell-Lloc & $63 \times 34 \times 17$ \\
\hline Cerro de los Santos ....... & 13 & $\begin{array}{l}\text { Benassal } \\
\text { Canet }\end{array}$ & $\begin{array}{l}44 \times 34 \times 11 \\
65 \times 32 \times 10\end{array}$ \\
\hline
\end{tabular}

Ares del Maestre ..... $84 \times 18,5 \times 10$

Espejo .............. $43 \times 26 \times 11 / 24$

Cerro Molinillos ...... $44 \times 17 \times 11$
Acéfala

Acéfala

Incompleta

Correlación de dimensiones según la bibliografía. Las medidas se expresan en centímetros.

y con la moda alcanzada por este tipo de monumentos en todo el Mediterráneo Occidental. La estela de Altea la Vella, en un momento antiguo (siglo vi), la de Ares del Maeste, quizá de una etapa intermedia, y las epigráficas, de cronología más tardía, argumentan la hipótesis de que las técnicas y la estética propiamente ibéricas se adaptan a tiempos más recientes, sustituyendo la matriz o soporte del bloque prismático por la forma troncopiramidal, pero manteniendo la alusión a la silueta humana y conservando la anatomía fundamental: la diferenciación del volumen de la cabeza, marcando la transición del cuerpo mediante la oblicuidad de los hombros.

Ello no quiere decir que todas las piezas ibéricas con esta morfología sean necesariamente funerarias y obviamente la fortuna de hallazgos arropados con un contexto preciso, que hoy no disponemos, podrá ratificarlo o desechar la hipótesis propuesta.

Por último, algunas reflexiones sobre la cronología de la escultura de Espejo. Los motivos ornamentales son muy viejos, así como la técnica de incrustar otras materias. En la ejecución antómica se ha superado la técnica incisa para pasar a un relieve muy suave. El esquematismo general es otro detalle orientativo, pero tanto en la pieza de Castellón como en la de Espejo, faltan los rasgos esenciales: la cabeza. A tenor de la 
cronologia que, en términos generales, se puede aplicar a la escultura ibérica de carácter más esquemático y a su dominio en la Alta Andalucía, proponemos para esta pieza en concreto una fecha de hacia finales del siglo Iv a. C., conjugando, como se ha dicho, la tradición antigua y la asimilación de los influjos externos. 
BIBLIOGRAFIA

Álvarez Y otros (1980): "La espada de antenas de Alcorisa y la necrópolis de Fila de la Muela", Bajo Aragón Prehistoria, II, págs. 37-51.

Arasa, F. (1989): “Estela ibérica de Bell-Lloc», Arch. Preh. Lev., núm. XIX. Valencia, págs. 96-100.

Ballester ToRmo, I (1942): “Estela Ibérica labrada». La labor del SIP y su Museo en los años 1935 a 1939. Valencia, págs. 129-132.

BARCELO, J. A. (1988): Introducción al razonamiento estadístico aplicado en la Arqueología: "Un análisis de las estelas antropomorfas de la Península Ibérica», Trabajos de Prehistoria, vol. 45, págs. 51-85.

Castiella, A. (1977): La Edad del Hierro en Navarra y Rioja. Pamplona.

CINTAS, P. (1970): Manuel d'Archéologie Punique, 2 vols. Paris.

FATAS, G. (1975): "Una estela de guerrero con escudo en $V$ aparecida en las Cinco Villas de Aragón», Pyrenae, núm. 11, págs. 165-169.

Estevez, F. (1989): "La lápida ibérica de Cabanes", Arch. Preh. Lev., vol. XIX, págs. 103-115.

FletCheR, D. (1985): “Textos ibéricos del Museo de Prehistoria de Valencia», Serie de Trab. Varios del S.I.P., núm. 81 , págs. 24 y ss.

Gómez Bellard, C. (1990): "La colonización fenicia de la Isla de Ibiza», Exc. Arq. Esp., núm. 157.

MARCo Simón, F. (1978): "Las estelas decoradas del Convento Caesaraugustano y Cluniense", Caesaraugusta, núm. 43-44, págs. 5-256.

Martín Bueno, M. y Pellicer, M. (1979/80): “Nuevas estelas proceden-

tes de Caspe (Zaragoza)", Habis, núm. 10/11, págs. 401-428.

MAYA, J. L. (1977): Lérida Prehistórica. Lérida.

MorenA, J. A. (1989): El santuario ibérico de Torreparedones (Castro del Río-Baena, Córdoba). Córdoba. 
Morote, G. (1981): “Una estela de guerrero con espada de antenas en la necrópolis ibérica de Altea la Vella (Alicante)", Arch. Preh. Lev., 16, págs. 417-446.

Oliver, A. (1978): “Epigrafía ibérica de la provincia de Castellón», Cuad. Preh. y Arq. Castellonenses, núm. V, págs. 264-291.

PitA, R. y Díz Coronel, L. (1968): “La necrópolis de Roques de San Formatges en Serós (Lérida)", Exc. Arq. Esp., núm. 59.

Ruano, E. (1981): "Aproximación a un catálogo de escultura ibérica en la provincia de Córdoba», Bol. As. Esp. A. A, 13, págs. 42-50.

- (1987): La escultura humana de piedra en el mundo ibérico, 3 vols. Madrid.

- (1990): «Fragmento de estela con relieve procedente de Mas de las Matas (Teruel)", Mas de las Matas, núm. X, Grupo de Estudios Masinos, págs. 99-110.

- Ruano, E. y SAN Nicolás, M.: "Exvotos ibéricos prodedentes de La Encarnación (Caravaca, Murcia)», Homenaje a Emeterio Cuadrado. Murcia (en prensa).

Santos Gener, S. (1950): Guía del Museo Arqueológico Provincial de Córdoba. Madrid.

TAfFanel, O. y M. J. (1960): “Deux tombes de chefs á Mailhac (Aude)», Gallia, XVIII, págs. 1-37.

Taracena, B. (1940-41): «La antigua población de la Rioja», Arch. Esp. de Arq. núm. XIV, págs. 157-177.

SOLVER y otros (1976): "La nécropole de "Las Peyros" Vle. siècle av. J. C., à Coffoulens (Aude)", Rev. Arch. Narb, Sup. 4.

WERnER, T. (1984): Typentafeln zu Ur-und Frühgeschichte Mitteleuropas. Hallstattkultur. Göttingen. 